\title{
Research and Practice of Teaching Analog Circuit for Foreign Students
}

\author{
Fangni Chen,Zhongpeng Wang, Weiwei Qiu \\ Zhejiang University of Science and Technology,Hangzhou, China \\ cfnini@163.com,wzp1966@sohu.com,weiweiqiu2015@163.om
}

\begin{abstract}
Along with the expansion of international higher education in China, the English teaching for foreign students has become the important way for foreign students education. This paper introduces teaching practices of Analog Circuit with English for foreign students, and discusses the teaching methods, the teachers' team building and the evaluation of teaching.Teaching practice shows that the learning interest of students and the teaching effects are improved greatly after the teaching reform.
\end{abstract}

Keywords-International student education; teaching reform; analog circuit

\section{INTRODUCTION}

Foreign students education is the inevitable development trend of Chinese higher education, and effective way of promoting the internationalization of education[1-2]. Analog circuit is one of the most important basis courses in communication engineering, electronic information engineering, automatic control and other similar specialties. In order to accelerate the teaching reform and promote the curriculum development, in this paper some opinions are proposed on the teaching methods, the teachers' team, the evaluation of teaching and so on. Teaching practice shows that the students' initiative and their interest are inspired, desirable teaching effects and students' high praises have been gained.

\section{The TEACHING STATE}

With the development of international communication market especially in developing countries of Asia and Africa, a large number of high-quality communications professionals are needed. In China the number of communication engineering related professional degree of overseas students is increasing year by year. Take Zhejiang University of Science and Technology as an example, in recent years, the students who major in communication engineering mainly come from the countries and regions of Asia and Africa. Compared with the domestic students, their characteristics are as follows.

\section{A. Different Knowledge Foundation}

Foreign students from the developing countries generally have the limitation of the weak education foundation, especially the mathematical basis. Also their knowledge of science is relatively narrow, and the ability of combining theory with practice is relatively low. However, the study of communication engineering requires not only a solid mathematical foundation, but also a particular emphasis on experimental and engineering practices to enhance practical ability. Therefore, how to teach foreign students in accordance with their aptitude is the most important problem we are facing.

\section{B. Communication Difficulties}

Teaching foreign students from developing countries will face the problem of language, because their Chinese is generally weak. We can not carry out the teaching in Chinese or bilingual teaching. And most of the students' mother language are not English and their English levels are uneven, even the whole English teaching also facing the difficulties in communication between teachers and students.

\section{Different cultural and Different Ways of Thinking}

Due to the different cultural backgrounds of foreign students, the students have different perspectives on issues, which make some expressions or views difficult to understand and influence the process of international teaching. Therefore, the solution to these problems is imminent.

\section{TEACHING REFORM METHODS}

The corresponding teaching contents should be updated with the development of communication technology. Teachers should select materials which can be able to catch up with the development of the current circuit technology. After multiple comparison we chose "Electronic devices and circuit theory" [3] written by Boylestad as the textbook, which can satisfy this requirement.

This research was financially supported by National Natural Science Foundation of China (Grant No. 61601409). 


\section{A. The Design of Teaching Content}

The course of Analog Circuit is a specialized basic course in the major of communication engineering. In the premise of ensuring the reasonable structure of knowledge[5], the theoretical teaching focuses on the analysis methods of typical circuits, and avoids the example of too complicated circuit analysis. This course requires a lot of exercises, and there are many examples and exercises in the textbook. Because the class time is limited, in the class we only talk about some important and typical examples. At the same time, in the example analysis, circuits used in the real life are selected to help students get to understand instead of using complex circuit. Also the circuit model analysis with relatively high requirements of mathematics and physics, such as the Fourier transform and Laplace transform are avoided in the class.

On the other hand, the practice teaching is also need to be strengthened, such as research on practice teaching methods, train the student's actual practice ability and the innovation ability. Analog circuit is a highly practical course, and it is difficult to make students learn it well only by theory teaching. In practice class, teachers must train students to learn how to analyze problems and solve problems, to encourage students to participate actively, to stimulate students' learning initiative and creativity. In the theoretical class, examples can pass to students who have already or will use in the practical course.

\section{B. Reform Teaching Methods}

Foreign students generally do not have the solid knowledge foundation as local students, so different teaching methods should be used. Once the students did not have a solid knowledge of the previous content, it will definitely have a bad influence towards the next learning, and it will greatly strike their self-confidence in learning. In the course of teaching, we can use heuristic teaching, discussion teaching or exercises, quizzes and many other forms. For students with poor mathematical basis, but lively personality, teachers should ask more questions and do more discussions in the class. Students are encouraged to write their answers on the blackboard, and then carry out the discussion, in order to increase the classroom activity to improve the students' enthusiasm and initiative in learning.

With the popularity of multimedia teaching, most colleges and universities now use multimedia teaching methods. Analog Circuit should adopt this approach too. The main benefits are as follows: Firstly, good courseware can save plenty of class time for teachers writing or drawing on the blackboard. It can expand teaching capacity, accelerate teaching rhythm and facilitate comparison of class contents[4]. Secondly, by adding the super link, the maps, text, voice, animation, simulation software [5] and other forms of embedded multimedia into the courseware, the abstract contents is visualization and vivid and make it easy to understand and accept for students. As the multimedia teaching may proceeds fast than traditional blackboard teaching, it's not easy for students to focus on the key point and to get a deep impression of the lessons. So teachers should pay attention to the integration with the traditional blackboard teaching when utilizing multimedia teaching methods. Writing the outline contents of each lesson, the important circuit structure, formula and conclusions on the blackboard for students may help them a lot.

\section{Building of teaching team}

The building of teaching team in colleges and universities is an important part of improving teaching quality and an important link in the process of educational reform. We need to select some teachers with good English, even more select those who have experience of studying and researching in foreign countries to undertake the teaching and management of foreign students. Each semester we will hire foreign researchers give English training for our teachers and select outstanding teachers to study abroad, in order to improve their ability of using English in teaching.

\section{Evaluation methods}

The curriculum reform is a dynamic process, which needs to adopt reasonable and effective evaluation methods to carry out fair and comprehensive evaluation, and further adjust the curriculum teaching design according to the evaluation results[4]. In order to help students to study better and effectively track students' knowledge of what they have been taught, teachers must strictly check students' attendance and conduct occasional quizzes. Consider students' usual performance (including attendance, homework and quizzes) in the final grades and emphasize their usual performance. The purpose is to let students pay more attention to the accumulation of learning.

\section{SUMMARY}

Different from teaching local students, it need higher requirements for teachers in China to give the English teaching to foreign students. In order to accelerate the international teaching reform and promote the international curriculum development, in this paper some opinions are proposed on the selection of teaching content, teaching methods and evaluation methods to improve the teaching quality and provide ideas as reference for intentional education. The students' initiative and their interest are inspired, desirable teaching effects and students' high praises have been gained in the practical teaching process. 


\section{REFERENCES}

[1] Z. Qin, L. Zhang, J. Luo, Y.J. Zeng, The practice of teaching digital electronic technique for foreign students, Journal of EEE, vol.36, No.4, pp. 26-27, 2014.

[2] Y. Lu, G.Q. Li, H.H Chen, H.P. Liu, Research and Practice of English Teaching of Experiment of Circuit Analysis for Foreign Students, Research and exploration in laboratory, vol.35, No.11,pp.170-173, 2016.

[3] R.L.Boylestad, L.Nashelsky, Electronic devices and circuit theory, Pearson Inc., 2011.

[4] F.N. Chen, Teaching Reform in the Course of Communication Principles, Proceedings of IUCE 2010.

[5] F.N. Chen, Application of MATLAB in Teaching of High Frequency Circuits, Proceedings of IUCE 2010. 